VIEWPOINT

Joseph Millum, PhD Fogarty International Center, National Institutes of Health, Bethesda, Maryland; and Department of Bioethics, Clinical Center, National Institutes of Health, Bethesda, Maryland.

Barbara Sina, PhD Fogarty International Center, National Institutes of Health, Bethesda, Maryland.

Roger Glass, MD, PhD Fogarty International Center, National Institutes of Health, Bethesda, Maryland.

Corresponding Author: Joseph Millum, PhD, National Institutes of Health, Clinical Center Department of Bioethics/Fogarty International Center, 10 Center Dr, 10/1C118, Bethesda, MD 20892 (millumj@cc.nih.gov).

\title{
International Research Ethics Education
}

Nearly 20 years ago, a series of trials evaluating shortcourse zidovudine for the prevention of mother-tochild transmission of human immunodeficiency virus (HIV) provoked global controversy when the sponsors were accused of ethical double standards-conducting research on vulnerable developing country populations that would not be permitted in high-income countries. ${ }^{1}$ Following this controversy, and responding to underrepresentation of developing countries in these debates, the Fogarty International Center at the $\mathrm{Na}$ tional Institutes of Health ( $\mathrm{NIH}$ ) launched a grants program to support masters-level, socioculturally relevant training in research ethics in low- and middle-income countries (LMICs).

Since the program began, the volume of research in LMICs and the funds devoted to global health have expanded substantially. ${ }^{2,3}$ The majority of the research is still sponsored by institutions based in high-income countries, including pharmaceutical companies, governmental agencies like $\mathrm{NIH}$, and private foundations. Some of the increase in LMIC-based research results from greater funding for diseases that affect people in these countries; some is a result of private companies seeking lower costs and patients naive to treatment. ${ }^{2,4} \mathrm{New}$ challenges have emerged, as LMICs increasingly must address the dual burden of communicable and noncommunicable diseases. New technologies, including widespread access to mobile phones and the decreasing cost of genomic analysis, have expanded the scope of research. Ethical controversies continue to arise, tarnishing the reputation of global health research and, in some countries, halting research altogether.

In the face of these changes, grantees, program staff, and outside experts conducted a collaborative selfassessment of the Fogarty International Center program 12 years after its inception. Fourteen articles present this extensive evaluation. ${ }^{5,6}$ The authors examine the state of research ethics in LMICs, summarize the lessons learned, identify future needs, and attempt to chart a way forward to address them.

Despite significant progress, the mission of building research ethics capacity in LMICs is not finished. However, the landscape of research and research ethics is substantially different than in 2000. New approaches are needed to build on what has been achieved and respond to new challenges.

The State of Research Ethics in LMICs

From 2000 to 2010, with the support of other $\mathrm{NIH}$ institutes and US government agencies, 20 training programs graduated approximately 600 masters-level trainees from 74 institutions in LMICs. ${ }^{7}$ The largest numbers were from programs focused on single countries, including 76 from South Africa, 72 from Nigeria, 71 from India, and 41 from Egypt. The largest proportion of awards (18/48, or $37.5 \%$ ) and $40 \%$ of program funding focused on sub-Saharan Africa, which was thought to have the least research ethics capacity in 2000. Among the 60 grants funded through 2011, 26 awards (43\%) were awarded directly to LMIC institutions.

Some additional sources of support for research ethics activities in LMICs are now available. These include the Society and Ethics program of the Wellcome Trust, the ethics and regulatory projects of the European and Developing Countries Clinical Trials Partnership, and the Human Heredity and Health in Africa Ethical, Legal, and Societal Issues Research Program of NIH (H3Africa ELSI). However, support for foundational activities in research ethics (ie, education and review) and for career development of bioethicists in LMICs remains limited.

During the last decade, the scope of ethical concerns about health research in LMICs has expanded and the discussion has become more sophisticated. The research community and wider public continue to express concerns about informed consent, standards of care, potential exploitation, and the imposition of Western views and regulatory systems on other countries. Much discussion has focused on the care that research participants should receive during and after trials and how communities that host research will benefit. As multinational research has increased, further pressing issues have emerged, including the involvement of LMIC stakeholders in setting research priorities, public-private collaborations, and the ownership of data and tissues. Concerns about the mistreatment of research participants has fueled regulatory changes and halted research in countries from Costa Rica to India.

\section{Future Vision and Strategies}

In essence, the vision for research ethics education should remain the same: LMIC institutions should be supported to develop and maintain expertise in research ethics as a foundation for strong and equal collaboration in global health research. Strategic changes are now required to reach the next level in realizing this vision.

First, more in-depth ethics expertise is needed in LMICs for ethical review of research. As trainees have graduated and moved into leadership positions, as the number of trainees in research-rich locations has increased, and as the research infrastructure in many countries has developed, the simple building of awareness has become less important. In addition, short online courses in research ethics now reach many researchers. However, there are still insufficient individuals with expertise in ethics to populate the research ethics committees of LMICs. Moreover, the amount of health research conducted in LMICs continues to increase, leading to even greater need for expert ethics review. An ideal goal 
is to have 1 committee member with in-depth ethics training serving on each high-volume-workload research ethics committee. Achieving this goal will require continued support for masterslevel training and investment in building LMIC institutional capacity to train individuals at this level.

Second, the challenging ethics of international research in HIV/ AIDS, genetics, mental health, addiction, health systems, and many more fields demand increased LMIC leadership. Even though individuals from LMICs contributed to discussions of research ethics more than 15 years ago, the dialogue, conceptual analysis, and development of international guidance remains dominated by those from high-income countries. To inform decision making on the issues most important to them, LMICs need the capacity to engage in empirical and conceptual research in ethics. Achieving this goal will require support for LMIC academic expertise in research ethics, ie, $\mathrm{PhD}$ and postdoctoral training, as well as career paths for research ethicists.

Third, many Fogarty International Center trainees face limited institutional commitment, financial support, and professional recognition for teaching research ethics or participating in the ethical review of research. The momentum of expertise gained, and the services they perform, will dissipate if trainees are not supported in their countries. Research ethics in LMICs needs a business plan that can ensure sustainability. Novel funding mechanisms should be identified so that the sponsors and institutions that support health research will support the ethical oversight this research requires. For example, this might entail charging fees for ethics review and allowing grantees to cover the costs of review as overhead.

Fourth, new health research regulations and guidelines regularly emerge from LMICs and international organizations. However, most health research enterprises are far from achieving efficient and transparent systems that demonstrably protect research participants. Research ethics should not be thought of as a committee, but as a set of values underlying health research, alongside the responsible conduct of research and clinical ethics. The principles of research ethics should be an integral and continuous component of research training and practice for all involved in the research enterprise. Everyone involved in research, from researchers and students, to research ethics committee administrators, institu- tional officials, and regulatory stakeholders, should receive some rolespecific ethics training. Further context-specific resources that are culturally appropriate and reflect LMIC issues should be developed for these educational needs. In-person education can now be supplemented by the wide range of distance learning methods that have been developed and tested in LMIC settings.

\section{Conclusions}

The work of the Fogarty grantees has generated models for effective international research ethics education. With partners around the world, the grantees have transformed the research ethics landscape. However, the world of health research has also evolved. Highly publicized problems with research in LMICs, from Guatemala to India, underscore the critical value of effective national systems to ensure that all studies meet international standards. Similarly, discussions of how to test new drugs and vaccines for diseases like Ebola illustrate the ongoing ethical challenges of conducting research on humans. Unless the research community responds to the ongoing and emerging needs in ethics, it risks further scandals, the halting or delaying of valuable research, and unethical research practices.

The vision of Fogarty International Center for the next decade of research ethics education is encapsulated in the 4 proposed goals: (1) ensure sufficient expertise in ethics review by having someone with long-term training on every high-workload research ethics committee, (2) develop LMIC capacity to conduct original research on critical ethical issues by supporting doctoral and postdoctoral training and career paths for research ethicists, (3) make research training and review at LMIC institutions sustainable by identifying additional funding mechanisms and models, and (4) make institutional research systems more ethical and efficient through contextspecific training integrated into all levels of scientific training. Achieving these goals will require coordinating the Fogarty International Center's efforts with those of others sponsors and will require continued support from the LMICs. As LMICs become independent sponsors of research, they need to simultaneously support building research ethics systems. Dialogue about our respective visions and coordinated action in achieving them are essential to ensure a future of ethical global health research.

\section{ARTICLE INFORMATION}

Conflict of Interest Disclosures: All authors have completed and submitted the ICMJE Form for Disclosure of Potential Conflicts of Interest and none were reported.

Funding/Support: This research was supported by the Intramural Research Program of the $\mathrm{NIH}$ Fogarty International Center, and Clinical Center.

Role of the Funder/Sponsor: The funding sources had no role in the preparation, review, or approval of the manuscript.

Disclaimer: The views expressed are the authors' own. They do not represent the position or policy of the National Institutes of Health, US Public Health Service, or the Department of Health and Human Services.

\section{REFERENCES}

1. Lurie $P$, Wolfe $S M$. Unethical trials of interventions to reduce perinatal transmission of the human immunodeficiency virus in developing countries. N Engl J Med. 1997;337(12):853-856.

2. Glickman SW, McHutchison JG, Peterson ED, et al. Ethical and scientific implications of the globalization of clinical research. N Engl J Med. 2009;360(8):816-823.

3. Wexler A, Kates J. The US global health budget analysis of appropriations for fiscal year 2015. Henry J. Kaiser Family Foundation. http://kff.org /global-health-policy/issue-brief/the -u-s-global-health-budget-analysis-of -appropriations-for-fiscal-year-2015/. Accessed January 15, 2015
4. Bollyky TJ, Cockburn IM, Berndt E. Bridging the gap: improving clinical development and the regulatory pathways for health products for neglected diseases. Clin Trials. 2010;7(6):719-734.

5. Glass R. International research ethics education. J Empir Res Hum Res Ethics. 2013;8(5):1-2.

6. Millum J, Sina B. Introduction: international research ethics education. J Empir Res Hum Res Ethics. 2014;9(2):1-2.

7. Matar A, Garner S, Millum J, Sina B, Silverman $H$. Curricular aspects of the Fogarty bioethics international training programs. J Empir Res Hum Res Ethics. 2014;9(2):12-23. 